\title{
Symmetrical Diamidate Prodrugs of Nucleotide Analogues for Drug Delivery
}

Fabrizio Pertusati ${ }^{1 *}$, Christopher McGuigan ${ }^{1}$ and Michaela Serpi ${ }^{1}$

E-mail: sphfp2@cardiff.ac.uk

${ }^{1}$ School of Pharmacy and Pharmaceutical Sciences, Cardiff University, King Edward VII Avenue, Cardiff CF10 3XF, United Kingdom.

\begin{abstract}
The use of pronucleotides to circumvent the well-known drawbacks of nucleotide analogues has played a significant role in the area of antiviral and anticancer drug delivery. Several motifs have been designed to mask the negative charges on the phosphorus moiety of either nucleoside monophosphates or nucleoside phosphonates, in order to increase their hydrophobicity and allow entry of the compound into the cell. Among them the bis-amidate analogues, having two identical amino acids as masking groups through a $\mathrm{P}-\mathrm{N}$ bond, represent a more recent approach for the delivery of nucleotide analogues, endowed with antiviral or anticancer activity. Two synthetic strategies are commonly used for preparing phosphorodiamidates of nucleosides. Both techniques will be here described using two nucleosides as model substrates: Stavudine and Acadesine. A third strategy for preparing diamidates of nucleoside phosphonates will be reported using Adefovir as model substrate.
\end{abstract}

Keywords: Phosphorodiamidates, nucleoside, phosphonate, antiviral, bis-amidate. 


\section{INTRODUCTION}

In order to achieve oral bioavailability and intracellular delivery of nucleoside monophosphates and phosphonates of antiviral and anticancer interest, numerous prodrug strategies have been explored. Using various approaches the ionizable phosphate group can be masked by derivatization, thus generating pronucleotides with increased lipophilicity. (Aziza et al. 2005; Wagner et al. 2000; Schultz et al. 2003; Pertusati et al. 2012; Peterson et al. 2009; Li et al. 2007; Krise et al. 1996; Hecker et al. 2008; He et al. 2007) The rationale behind the design of such agents is to achieve temporary blockage of the free phosphoric or phosphonic functional group until their systemic absorption and delivery, allowing the release of free drug only once at the target. Among all the different classes of prodrugs the ProTide approach developed by McGuigan group (Mcguigan et al. 1993) including both aryloxy mono-amidate (Serpi et al. 2013) and bisamidate derivatives has been proved to boost the activity of parent nucleosides by increasing the formation rate of nucleoside triphosphates, by improving intracellular transport and/or bypassing the rate limiting monophosphorylation step (Derudas et al. 2009; Mcguigan et al. 2010; McGuigan et al. 2011; Mehellou et al 2009; Slusarczyk et al. 2014; Toti et al. 2014; Serpi et al. 2012; McGuigan et al. 2014). Several leading pharmaceutical companies have already applied the pioneering aryloxy mono-amidate technology for anti-viral and anticancer treatments.

More recently the phosphorodiamidate technology applied to several anticancer and antiviral nucleoside analogues was also reported as a new successful approach for the delivery of monophosphates inside the cell (McGuigan et al. 2013; McGuigan et al., 2011). In this approach two amino acid esters are introduced on the monophosphate moiety in order to mask the negative charges. Bis-amidates derivatives offer two distinct advantages when compared to the aryloxy mono-amidate analogues. Due to their symmetric structure no phosphorus chirality arises, and exclusively non-toxic 
promoieties are released during the prodrug bioactivation. This novel prodrug approach has been validated both in vitro and in vivo and some compounds are already under consideration for clinical studies. Among them, GS-9191 active against papilloma viruses is now under clinical development (Phase I clinical trials) by Gilead science as a topical prodrug for the treatment of HPV lesions (Wolfgang et al. 2009).

Herein we present a strategy for obtaining the phosphorodiamidate prodrugs. The method involve the phosphorylation of nucleoside by phosphorus oxychloride $\left(\mathrm{POCl}_{3}\right)$ in tetrahydrofuran (THF) in the presence of triethylamine, followed by reaction with an excess of the appropriate amino acid ester as $p$-toluene sulfonate (p-TSA) salt in the presence of triethylamine (McGuigan et al. 2013; McGuigan et al. 2011]. The model compounds employed was 2'-3'-didehydro-2'-3'-dideoxythymidine (d4T, stavudine), a nucleoside analogue approved for the treatment of HIV infection. Additionally, we report the application of a more recent synthetic methodology to prepare phosphonodiamidate derivatives, starting from free phosphonic acid of $\{[2-(6$-amino9H-purin-9-yl)ethoxy]methyl\}phosphonic acid (PMEA, adefovir) via bis-trimethylsilyl ester intermediates (Basic Protocol 2) (Jansa et al. 2011; Pertusati et al.; 2014). Adefovir is a potent ANP endowed with antiviral activity and currently its bis (pivaloy-loxymethyl) ester (bis-(POM)-PMEA; Hepsera $\left.{ }^{\circledR}\right)$ is on the market for the treatment of $\mathrm{HBV}$ infections (Starrett et al. 1994).

CAUTION: Carry out all operations involving organic solvents and reagents in a wellventilated fume hood. Wear appropriate protective clothing and eye/face protection. NOTE: All glassware should be oven dried, and all reactions should be performed under anhydrous conditions. For the synthesis of the amino acid ester not commercially available please see see Support Protocol unit 15.5.8 (Serpi et al. 2013).

\section{BASIC PROTOCOL 1}




\section{Preparation of bis-amidate prodrugs of $2^{\prime}, 3^{\prime}$-didehydro- $2^{\prime}, 3^{\prime}$-dideoxythymidine}

This protocol describes the synthesis of bis-amidate prodrugs of $\mathrm{d} 4 \mathrm{~T}$ nucleoside. In this strategy, the unprotected nucleoside (1 equiv.) dissolved in THF is treated with phosphorus oxychloride ( 1 equiv.) in the presence of triethylamine (1 equiv.) to generate a phosphorodichloridate intermediate 2 ( ${ }^{31} \mathrm{P}-\mathrm{NMR}$ signal at $\sim 7-8 \mathrm{ppm}$ reference to $\mathrm{H}_{3} \mathrm{PO}_{4}$ ), which is not isolated. Then, an excess of the appropriate amino acid ester as $p$-toluene sulfonate ( $p$-TSA) salt (5 eq.) and triethylamine (5 eq.) are added at $-78{ }^{\circ} \mathrm{C}$, leading after 18 to 20 hours at room temperature to the desired phosphorodiamidate 3a, $\mathbf{b}$ ( ${ }^{11} \mathrm{P}-\mathrm{NMR}$ signals at $\delta \mathrm{p} \sim 12-14 \mathrm{ppm}$ ) (Figure 1). In the case of $\mathbf{1}$ only the $5^{\prime}-\mathrm{OH}$ is present. In case of nucleoside having more reactive hydroxyl group, either alternate Protocol 2 or selective protection procedures are recommended.

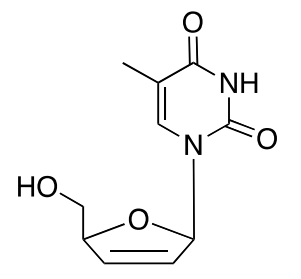

1

$\mathrm{CH}_{2} \mathrm{Cl}_{2}, \mathrm{Et}_{3} \mathrm{~N},(L)-\mathrm{AlaO} c-\mathrm{Hexyl} p \mathrm{TsOH}$ or (L)-AlaOCH${ }_{2}$ tBu $p \mathrm{TsOH},-78^{\circ} \mathrm{C}$ to rt, $12 \mathrm{~h}$
$\mathrm{POCl}_{3}, \mathrm{Et}_{3} \mathrm{~N} \mathrm{THF}$,
$-78^{\circ} \mathrm{C}$ to rt, $5 \mathrm{~h}$

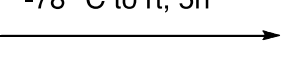

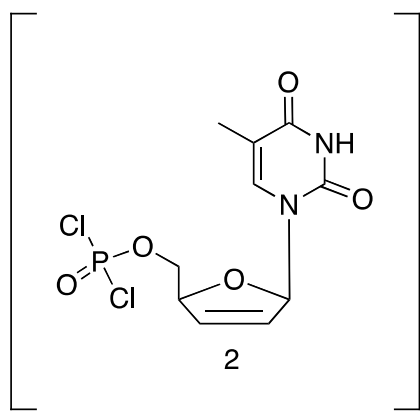

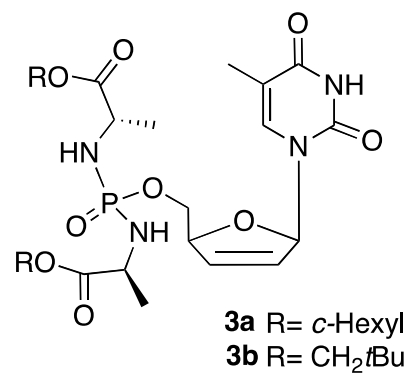

Figure 1. Synthesis of d4T phosphordiamidates $(\mathbf{3 a}, \mathbf{b})$.

\section{Materials}

Anhydrous dichloromethane $\left(\mathrm{CH}_{2} \mathrm{Cl}_{2}\right)$ (Sigma-Aldrich)

Anhydrous tetrahydrofuran (THF) (Sigma-Aldrich) 
Triethylamine (Et $3 \mathrm{~N})$ (Sigma-Aldrich)

Phosphoryl chloride ( $\left.\mathrm{POCl}_{3}\right)$ (Sigma-Aldrich)

(L)-Alanine cyclohexyl ester $p$-toluensulfonate (see Support Protocol unit 15.5.8)

(L)-Alanine 2,2-dimethylpropylester $p$-toluensulfonate (see Support Protocol unit 15.5.8)

2'-3'-Didehydro-2'-3'-dideoxythymidine (d4T, Stavudine, Carbosynth)

Dichloromethane (Fluka)

Methanol (Fluka)

Dry nitrogen $\left(\mathrm{N}_{2}\right)$ or Argon (Ar)

Anhydrous $\mathrm{Na}_{2} \mathrm{SO}_{4}$ (Sigma-Aldrich)

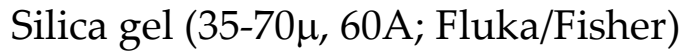

Sand (Sigma-Aldrich)

50-, 100-, and 500-mL round-bottom flasks

Magnetic stirrer plate

Dry ice/Acetone bath

Analytical TLC plate (aluminum-backed TLC plates, precoated with silica gel 60

F254, 0.2 mm; Merck Kieselgel)

250-mL separating funnel

Glass funnel

Filter paper

Rotary evaporator equipped with vacuum pump (BUCHI)

Vacuum desiccator

Chromatography columns: 2.5 x 30-cm

UV light source

$\mathrm{MeOH}-\mathrm{d}_{4}$ (Goss)

Acetonitrile HPLC grade (FISHER)

Water HPLC grade (FISHER) 
Varian Pursuit XRs 5 C18, $150 \times 4.6$ mm

Bruker Daltonics microTof-LC, (electron spray ionization) in positive mode

Bruker Avance 500 NMR spectrometer

Thermo SCIENTIFIC, SPECTRA SYSTEM P4000, detector SPECTRA SYSTEM UV2000

1. In a $25 \mathrm{~mL}$ round bottom flask, prepare a solution of $0.5 \mathrm{~g} \mathbf{1}(2.23 \mathrm{mmol})$ in anhydrous THF (5 mL) under an Argon atmosphere.

2. Add $0.31 \mathrm{~mL}$ anhydrous $\mathrm{Et}{ }_{3} \mathrm{~N}(2.23 \mathrm{mmol})$ under an argon atmosphere.

3. Stir at room temperature for $30 \mathrm{~min}$ and then add $0.21 \mathrm{~mL} \mathrm{POCl}_{3}(2.23$ mmol) dropwise at $-78{ }^{\circ} \mathrm{C}$.

4. Stir the reaction mixture at $-78{ }^{\circ} \mathrm{C}$ for $30 \mathrm{~min}$ and then allow to reach room temperature in $1 \mathrm{~h}$.

5. After $5 \mathrm{~h}$, monitor the reaction by ${ }^{31} \mathrm{P}-\mathrm{NMR}$ using a $\mathrm{CDCl}_{3}$ as an internal standard and to achieve lock. Leave the reaction longer if $\mathrm{POCl}_{3}$ (singlet at $\sim 4 \mathrm{ppm}$ ) is still present along with the desired phosphorylated nucleoside 2 (singlet at $\sim 6 \mathrm{ppm}$ ).

5. Once completion of the reaction is confirmed by ${ }^{31} \mathrm{P} \mathrm{NMR}$, dilute the solution with anhydrous $\mathrm{CH}_{2} \mathrm{Cl}_{2}(10 \mathrm{~mL})$ and add $3.82 \mathrm{~g}(L)$-alanine cyclohexylester $p$-toluensulfonate salt $(11.15 \mathrm{mmol})$ for $3 \mathrm{a}$ and $3.69 \mathrm{~g}$ (L)-alanine 2,2-dimethylpropylester $p$-toluensulfonate salt $(11.15 \mathrm{mmol})$ for $\mathbf{3 b}$.

6. Cool down the solution to $-78{ }^{\circ} \mathrm{C}$ and then add dropwise anhydrous 1.5 $\mathrm{mL} \mathrm{Et}{ }_{3} \mathrm{~N}(11.15 \mathrm{mmol})$.

7. Stir the reaction mixture at room temperature for $12 \mathrm{~h}$.

8. Add $\mathrm{H}_{2} \mathrm{O}(4 \mathrm{~mL})$ and extract the aqueous phase with $\mathrm{CH}_{2} \mathrm{Cl}_{2}(2 \times 5 \mathrm{~mL})$.

9. Wash the organic phase with brine $(4 \mathrm{~mL})$, dry over anhydrous $\mathrm{MgSO}_{4}$. 
Filter and evaporate to dryness.

10. Prepare silica gel (45 g) slurry for flash chromatography in $\mathrm{CH}_{2} \mathrm{Cl}_{2}$. Pour the slurry into a $2.5 \times 30 \mathrm{~cm}$ chromatography column.

11. Dissolve the crude product in the minimum amount of $\mathrm{CH}_{2} \mathrm{Cl}_{2}$ and carefully place the solution on top of the column. Layer $1.5 \mathrm{~cm}$ of sand on top of the column.

12. Elute the first $250 \mathrm{~mL}$ with $98: 2(\mathrm{v} / \mathrm{v}) \mathrm{CH}_{2} \mathrm{Cl}_{2} / \mathrm{MeOH}$, change to $97: 3(\mathrm{v} / \mathrm{v})$ $\mathrm{CH}_{2} \mathrm{Cl}_{2} / \mathrm{MeOH}(250 \mathrm{~mL})$ and then to $95: 5$ (v/v/) $\mathrm{CH}_{2} \mathrm{Cl}_{2} / \mathrm{MeOH}$ to elute the desired product.

13. Monitor the fractions by TLC using 9:1 (V/V) $\left.\mathrm{CH}_{2} \mathrm{Cl}_{2} / \mathrm{MeOH}_{(\mathrm{f}}=0.30\right)$ as elution solvent and visualize by UV light. Combine the fractions containing pure products and evaporate to dryness using a rotary evaporator under reduced pressure to obtain $\mathbf{3 a}, \mathbf{b}$.

14. Dry the pure compounds under vacuum (20 mbar) for $12 \mathrm{~h}$.

15. Characterize the compounds by ${ }^{1} \mathrm{H},{ }^{13} \mathrm{C},{ }^{31} \mathrm{P}$ NMR and HRMS.

16. Check the purity of the compound by reverse phase HPLC

Phosphoramidate derivatives of $d 4 \mathrm{~T}$ are stable for several years when stored at $-20^{\circ} \mathrm{C}$ under argon atmosphere.

${ }^{31} \mathrm{P}$ NMR spectra documented below were obtained with proton decoupling. d4T-5'-O-bis-(cyclohexyloxy-L-alaninyl)-phosphate (3a). yield of white solid $0.66 \mathrm{~g}(46 \%) .{ }^{1} \mathrm{H}$ NMR (500 MHz, MeOH-d $)_{4} \delta_{H} 7.44(s, 1 H, H-6), 6.99\left(m, 1 H, H-1^{\prime}\right), 6.45$ (dd, J = 6.0, $1.2 \mathrm{~Hz}$, $\left.1 H, H-3^{\prime}\right), 5.99\left(d d, J=6.0,1.2 \mathrm{~Hz}, 1 H, H-2^{\prime}\right), 5.02\left(b s, 1 H, H-4^{\prime}\right), 4.78-4.74(m, 2 H, 2 x$ $\mathrm{OCH}), 4.21-4.14\left(\mathrm{~m}, 2 \mathrm{H}, \mathrm{H}-5^{\prime}\right), 3.90-3.84\left(\mathrm{~m}, 2 \mathrm{H}, \mathrm{CHCH}_{3}\right), 1.92\left(\mathrm{~s}, 3 \mathrm{H}, \mathrm{CH}_{3}\right), 1.90-1.80(\mathrm{~m}$, $4 H, c H x), 1.80-1.70(m, 4 H, c H x), 1.63-1.55(m, 2 H, c H x), 1.54-1.29(m, 10 H, c H x), 1.36(d)=$ $\left.7.0 \mathrm{~Hz}, 3 \mathrm{H}, \mathrm{CHCH}_{3}\right), 1.32\left(d, \mathrm{~J}=7.0 \mathrm{~Hz}, 3 \mathrm{H}, \mathrm{CHCH}_{3}\right) .{ }^{13} \mathrm{C} \mathrm{NMR}\left(125 \mathrm{MHz}, \mathrm{MeOH}-d_{4}\right), \delta_{\mathrm{c}}=$ $175.05\left(d,{ }^{3} J_{C-P}=5.0 \mathrm{~Hz}, C=O\right), 174.89\left(d,{ }^{3} \mathrm{C}_{\mathrm{C}-P}=5.0 \mathrm{~Hz}, \mathrm{C}=\mathrm{O}\right), 166.37(\mathrm{C}-4), 152.81(\mathrm{C}-2)$, 
$137.97(C-6), 134.98\left(C-3^{\prime}\right), 127.95\left(C-2^{\prime}\right), 112.14(C-5), 91.21\left(C-1^{\prime}\right), 86.57\left(d^{3}{ }^{3} \mathrm{~J}-\mathrm{P}=8.75 \mathrm{~Hz}\right.$, C-4') , 74.88, $74.86(2 x \mathrm{OCH}), 67.44\left(d,{ }^{2} \mathrm{~J}_{\mathrm{C}-\mathrm{P}}=5.0 \mathrm{~Hz}, \mathrm{C}-5^{\prime}\right), 51.22\left(d,{ }^{2} \mathrm{~J}_{\mathrm{C}-\mathrm{P}}=1.12 \mathrm{~Hz}, \mathrm{CHCH}_{3}\right)$, $50.99\left(d,{ }^{2} J_{c-p}=1.12 \mathrm{~Hz}, \mathrm{CHCH}_{3}\right), 32.57,32.56,32.50,32.48\left(\mathrm{CH}_{2} \mathrm{cHx}\right), 26.48,24.75,24.72$, $24.68\left(\mathrm{CH}_{2} \mathrm{CH} x\right), 21.15\left(d^{3}{ }^{3} \mathrm{C}_{\mathrm{P}-\mathrm{P}}=5.0 \mathrm{~Hz}, \mathrm{CHCH}_{3}\right), 20.95\left(d^{3}{ }^{3} \mathrm{C}-\mathrm{P}=5.0 \mathrm{~Hz}, \mathrm{CHCH}_{3}\right), 12.73$ $\left(\mathrm{CH}_{3}\right) .{ }^{31} \mathrm{P} \mathrm{NMR}\left(202 \mathrm{MHz}, \mathrm{MeOH}-d_{4}\right) \delta_{\text {P }}$ 12.58. (ES+) m/z: $633.25\left(\mathrm{M}+\mathrm{Na}^{+}, 100 \%\right)$. Reverse HPLC, eluting with $\mathrm{H}_{2} \mathrm{O} / \mathrm{CH}_{3} \mathrm{CN}$ from 90:10 to 0:100 in $30 \mathrm{~min}$, Flow $=1 \mathrm{~mL} / \mathrm{min}, \mathrm{UV}$ Detector $=254 \mathrm{~nm}, t_{R}=18.48 \mathrm{~min}$.

d4T-5'-O-bis-(2,2-dimethylpropoxy-L-alaninyl)-phosphate (3b). Yield of white solid $0.15 \mathrm{~g}$ (12\%). ${ }^{1} \mathrm{H}$ NMR (500 MHz, MeOH-d 4 ) $\delta_{H} 7.44$ (s, 1H, H-6), 7.01-6.90 (m, 1H, H-1'), 6.46$6.40\left(m, 1 H, H-3^{\prime}\right), 6.00-5.90\left(m, 1 H, H-2^{\prime}\right), 5.03\left(b s, 1 H, H-4^{\prime}\right), 4.21-4.14\left(m, 2 H, H-5^{\prime}\right), 3.98-$ $3.92\left(m, 2 \mathrm{H}, 2 \times \mathrm{CHCH}_{3}\right), 3.91,3.89,3.78,3.76\left(2 x A B J_{A B}=10.05 \mathrm{~Hz}, 4 \mathrm{H}, 2 x\right.$ $\left.\mathrm{OCH}_{2} \mathrm{C}\left(\mathrm{CH}_{3}\right)_{3}\right), 1.92\left(\mathrm{~s}, 3 \mathrm{H}, \mathrm{CH}_{3}\right), 1.40\left(d, J=7.0 \mathrm{~Hz}, 6 \mathrm{H}, 2 x \mathrm{CHCH}_{3}\right), 0.976(\mathrm{~s}, 9 \mathrm{H}$, $\left.\mathrm{OCH}_{2} \mathrm{C}\left(\mathrm{CH}_{3}\right)_{3}\right), 0.972\left(\mathrm{~s}, 9 \mathrm{H}, \mathrm{OCH}_{2} \mathrm{C}\left(\mathrm{CH}_{3}\right)_{3}\right) .{ }^{13} \mathrm{C} \mathrm{NMR}\left(125 \mathrm{MHz}, \mathrm{MeOH}-d_{4}\right), \delta_{c}=175.64(d$, $\left.{ }^{3} J_{C-P}=5.0 \mathrm{~Hz}, C=O\right), 175.47\left(d,{ }^{3} J_{C-P}=5.0 \mathrm{~Hz}, C=O\right), 166.41(C-4), 152.85(C-2), 137.97(C-6)$, 134.98 (C-3'), 127.93 (C-2'), $112.14(C-5), 91.22\left(C-1^{\prime}\right), 86.57\left(d^{3}{ }^{3} C_{C-P}=8.75 \mathrm{~Hz}, C-4^{\prime}\right), 75.45(2$ $\left.x \mathrm{OCH}_{2} \mathrm{C}\left(\mathrm{CH}_{3}\right)_{3}\right), 67.54\left(d,{ }^{2} \mathrm{~J}_{\mathrm{C}-\mathrm{P}}=5.0 \mathrm{~Hz}, \mathrm{C}-5^{\prime}\right), 51.19\left(d,{ }^{2} \mathrm{~J}_{\mathrm{C}-\mathrm{P}}=1.12 \mathrm{~Hz}, \mathrm{CHCH}_{3}\right), 50.82\left({ }^{2},{ }^{2} \mathrm{Jc}-\right.$ $\left.p=1.12 \mathrm{~Hz}, \mathrm{CHCH}_{3}\right), 32.36\left(2 x \mathrm{OCH}_{2} \mathrm{C}\left(\mathrm{CH}_{3}\right)_{3}\right), 26.87,26.60\left(2 x \mathrm{OCH}_{2} \mathrm{C}\left(\mathrm{CH}_{3}\right)_{3}\right), 21.19\left(d,{ }^{3} \mathrm{Jc}-\right.$ $\left.p=5.0 \mathrm{~Hz}, \mathrm{CHCH}_{3}\right), 21.01\left(d^{3}{ }^{3} \mathrm{C}-\mathrm{P}=5.0 \mathrm{~Hz}, \mathrm{CHCH}_{3}\right), 12.71\left(\mathrm{CH}_{3}\right) .{ }^{31} \mathrm{P} \mathrm{NMR}(202 \mathrm{MHz}$,

$\left.\mathrm{MeOH}-d_{4}\right) \delta p$ 13.73. MS (ES+) m/z: $609.27\left(\mathrm{M}+\mathrm{Na}^{+}, 100 \%\right)$ Reverse-phase HPLC, eluting with $\mathrm{H}_{2} \mathrm{O} / \mathrm{CH}_{3} \mathrm{CN}$ from 90:10 to 0:100 in $30 \mathrm{~min}$, Flow $=1 \mathrm{~mL} / \mathrm{min},-=254 \mathrm{~nm}, t_{R}=17.80 \mathrm{~min}$.

\section{BASIC PROTOCOL 2}

Synthesis of bis-amidate prodrugs of \{[2-(6-amino-9H-purin-9yl)ethoxy]methyl\}phosphonic acid 
This protocol describes the preparation of bis-amidate produgs of Adefovir (Jansa et al. 2011). According to this methodology, overnight reaction of Adefovir (1eq) with trimethylsilyl bromide (5 eq) in acetonitrile $(10 \mathrm{~mL} / \mathrm{mmol})$ affords the intermediate bis(trimethylsilyl)-phosphonate ester 5, which once isolated without purification is reacted with an excess of the desired amino acid ester $(4 \mathrm{eq})$ in pyridine $(10 \mathrm{~mL} / \mathrm{mmol})$ in the presence of triethylamine (4 eq) aldrithiol-2 (6 eq) and triphenylphosphine (6 eq) (Figure 2). This two-steps reaction gives the corresponding (L)-Alanine diamidate prodrug 6 in 25\% overall yields, after purification by column chromatography. The reaction can be monitored by ${ }^{31} \mathrm{P}$ NMR spectroscopy analysis to ensure the completion of each step.
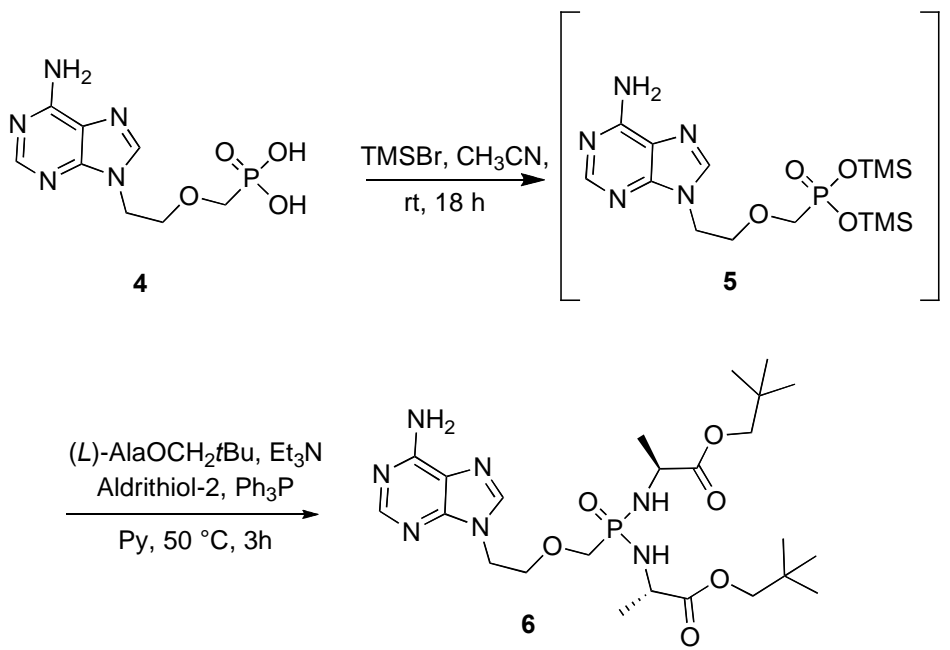

Figure 2. Synthesis of Adefovir phosphorodiamidates 6

\section{Materials}

Adefovir (Hubei Maxsource chemical Co., Ltd, Wuhan, China)

(L)-Alanine 2,2-dimethylpropylester $p$-toluensulfonate (see Support Protocol unit 15.5.8) Trimethylsilyl bromide (Sigma-Aldrich)

Anhydrous pyridine (Sigma-Aldrich)

Anhydrous acetonitrile (Sigma-Aldrich) 
Aldrithiol-2 (Sigma-Aldrich)

Triphenylphosphine (Sigma-Aldrich)

Dry nitrogen $\left(\mathrm{N}_{2}\right)$ or Argon (Ar)

Methanol (Fluka)

Toluene (Fluka)

Hexane (Fluka)

Ethyl acetate (Fluka)

Dichloromethane (Fluka)

Anhydrous $\mathrm{Na}_{2} \mathrm{SO}_{4}$ (Sigma-Aldrich)

Silica gel (35-70 $\mu, 60 \mathrm{~A}$; Fluka/Fisher)

Sand (Sigma-Aldrich)

50-, 100-, and 500-mL round-bottom flasks (Fisher)

Magnetic stirrer plate

Oil bath

Analytical TLC plate (aluminum-backed TLC plates, precoated with silica gel 60

F254, 0.2 mm; Merck Kieselgel)

250-mL separating funnel

Glass funnel

Filter paper

Rotary evaporator equipped with vacuum pump (BUCHI)

Sintered glass funnel

Vacuum desiccator

Chromatography columns: $5 \times 20-\mathrm{cm}$ and $4.5 \times 23-\mathrm{cm}$

UV light source

$\mathrm{MeOH}-\mathrm{d}_{4}$ (Goss)

Acetonitrile HPLC grade (FISHER) 
Water HPLC grade (FISHER)

Varian Pursuit XRs 5 C18, 150 x 4.6 mm

Bruker Daltonics microTof-LC, (electron spray ionization) in positive mode Bruker Avance 500 NMR spectrometer

ThermoSCIENTIFIC, SPECTRA SYSTEM P4000, detector SPECTRA SYSTEM UV2000

1. In a $25 \mathrm{~mL}$ round bottomed flask, prepare a solution of $0.2 \mathrm{~g}$ Adefovir $(0.73 \mathrm{mmol})$ in $7.3 \mathrm{~mL}$ of dry acetonitrile under Argon atmosphere.

2. Add $0.481 \mathrm{~mL}$ TMSBr $(3.65 \mathrm{mmol})$ under argon and stir the resulting mixture at rt overnight.

3. Remove the solvents under reduced pressure without any contact with air.

4. Dissolve the residue in $1.46 \mathrm{~mL}$ anhydrous $\mathrm{Et}_{3} \mathrm{~N}$ and $5.8 \mathrm{~mL}$ pyridine.

5. Add $1.35 \mathrm{~g}(L)$-alanine 2,2-dimethylpropylester $p$-toluensulfonate salt (2.92 $\mathrm{mmmol}$ ) and heat the reaction at $50{ }^{\circ} \mathrm{C}$ to obtain a homogeneous solution.

6. In a separated flask, dissolve $0.964 \mathrm{~g}$ Aldrithiol-2 (4.38 mmol) and $1.15 \mathrm{~g}$ triphenylphosphine $(4.38 \mathrm{mmol})$ in $7.3 \mathrm{~mL}$ anhydrous pyridine.

7. Add this solution to the reaction mixture under argon.

8. Stir the resulting mixture (green solution) at $50{ }^{\circ} \mathrm{C}$ for $3-5 \mathrm{~h}$.

9. Cool down the solution at rt and evaporate the solvents on the rotary evaporator.

10. Add a mixture of methanol, water, toluene and hexane 1:1:1:1 (10/10/10/10 $\mathrm{mL}$ ) to the residue and transfer the mixture into a separatory funnel.

11. Remove the upper layer (Hex/toluene) and wash the lower phase with a mixture of toluene and hexane 1:1 (v/v) three times.

12. Remove the upper layer and extract the lower layer $\left(\mathrm{MeOH} / \mathrm{H}_{2} \mathrm{O}\right)$ three times with ethyl acetate $(3 \times 20 \mathrm{~mL})$. 
13. Combine the ethyl acetate phase, dry over $\mathrm{MgSO}_{4}$, filter and evaporate.

14. Prepare silica gel (45 g) slurry for flash chromatography in $\mathrm{CH}_{2} \mathrm{Cl}_{2}$. Pour the slurry into a $2.5 \times 30 \mathrm{~cm}$ chromatography column.

15. Dissolve the crude product in the minimum amount of $\mathrm{CH}_{2} \mathrm{Cl}_{2}$ and carefully place the solution on top of the column. Layer $1.5 \mathrm{~cm}$ of sand on top of the column.

16. Elute the first $250 \mathrm{~mL}$ with $98: 2(\mathrm{v} / \mathrm{v}) \mathrm{CH}_{2} \mathrm{Cl}_{2} / \mathrm{MeOH}$, change to $97: 3(\mathrm{v} / \mathrm{v})$ $\mathrm{CH}_{2} \mathrm{Cl}_{2} / \mathrm{MeOH}(250 \mathrm{~mL})$ and then to $95: 5(\mathrm{v} / \mathrm{v} /) \mathrm{CH}_{2} \mathrm{Cl}_{2} / \mathrm{MeOH}$ to elute the desired product.

17. Monitor the fractions by TLC using 9:1 (V/V) $\left.\mathrm{CH}_{2} \mathrm{Cl}_{2} / \mathrm{MeOH}_{(\mathrm{f}}=0.34\right)$ as elution solvent and visualize by UV light. Combine the fractions containing pure products and evaporate to dryness using a rotary evaporator under reduced pressure to obtain 6 .

18. Dry the pure compound under vacuum for $12 \mathrm{~h}$

19. Characterize the compounds by ${ }^{1} \mathrm{H},{ }^{13} \mathrm{C},{ }^{31} \mathrm{P}$ NMR and HRMS.

20. Check the purity of the compound by reverse phase HPLC.

9-[2-(Phenyloxy-(2,2-dimethylpropoxy-L-alaninyl)-Phosphonomethoxy)ethyl]adenine. (6) Yield of an off-white solid $100 \mathrm{mg}(25 \%){ }^{1} \mathrm{H} N \mathrm{NMR}\left(500 \mathrm{MHz}, \mathrm{MeOH}-d_{4}\right): \delta 8.21$ (s, $\left.1 \mathrm{H}, \mathrm{H}-2\right), 8.20$ (s, 1H, H-2), 8.18 (s, 1H, H-8), $8.16(\mathrm{~s}, 1 \mathrm{H}, \mathrm{H}-8), 7.30-7.22(\mathrm{~m}, 4 \mathrm{H}, \mathrm{Ph}), 7.14(\mathrm{t}, \mathrm{J}=8.2 \mathrm{~Hz}, 2 \mathrm{H}$, Ph), $7.12(t, J=8.1 \mathrm{~Hz}, 2 \mathrm{H}, \mathrm{Ph}), 7.06(d, J=8.1 \mathrm{~Hz}, 2 \mathrm{H}, \mathrm{Ph}), 4.43\left(\mathrm{~m}, 4 \mathrm{H}, \mathrm{N}-\mathrm{CH}_{2}\right), 4.07-3.85$ $\left(m, 10 \mathrm{H}, \mathrm{CH}_{2}-\mathrm{P}, \mathrm{N}-\mathrm{CH}, \mathrm{OCH}_{2} \mathrm{CH}_{2} \mathrm{~N}\right), 3.81,3.71\left(\mathrm{AB}, \mathrm{J}_{A B}=10.0 \mathrm{~Hz}, 2 \mathrm{H}, \mathrm{OCH}_{2} \mathrm{C}\left(\mathrm{CH}_{3}\right)_{3}\right), 3.80$, $3.70\left(A B, J_{A B}=10.0 \mathrm{~Hz}, 2 \mathrm{H}, \mathrm{OCH}_{2} \mathrm{C}\left(\mathrm{CH}_{3}\right)_{3}\right), 1.29\left(d, J=7.3 \mathrm{~Hz}, 3 \mathrm{H}, \mathrm{CH}_{3}-\mathrm{aa}\right), 1.28(d, J=7.3$ $\left.\mathrm{Hz}, 3 \mathrm{H}, \mathrm{CH}_{3}-\mathrm{aa}\right), 0.95\left(\mathrm{~s}, 9 \mathrm{H}, \mathrm{C}\left(\mathrm{CH}_{3}\right)_{3}\right), 0.94\left(\mathrm{~s}, 9 \mathrm{H}, \mathrm{C}\left(\mathrm{CH}_{3}\right)_{3}\right)$ ppm. ${ }^{13} \mathrm{C}-\mathrm{NMR}(125 \mathrm{MHz}$, $\left.\mathrm{MeOH}-d_{4}\right): \delta 175.33\left(d,{ }^{3} \mathrm{C}_{\mathrm{C}-\mathrm{P}}=4.0 \mathrm{~Hz}, \mathrm{C}=\mathrm{O}\right), 175.09\left(d^{3}{ }^{3} \mathrm{C}_{\mathrm{C}-\mathrm{P}}=4.0 \mathrm{~Hz}, \mathrm{C}=\mathrm{O}\right), 157.32,157.30(\mathrm{C}-$ 6), 153.76, $153.72(\mathrm{CH}-2), 151.50\left(d,{ }^{2} \mathrm{C}_{\mathrm{C}-\mathrm{P}}=9.0 \mathrm{~Hz}, \mathrm{C}\right.$-ipso OPh$), 151.41\left(\mathrm{~d},{ }^{2} \mathrm{~J}_{\mathrm{C}-\mathrm{P}}=9.0 \mathrm{~Hz}, \mathrm{C}-\right.$ 
ipso OPh), 150.75, 150.73 (C-4), 143.41, $143.38(\mathrm{CH}-8), 130.76,130.74,126.17,126.11(\mathrm{Ph})$, $121.94\left(d,{ }^{3} J_{C-P}=4.5 \mathrm{~Hz}, \mathrm{Ph}\right), 121.76\left(d,{ }^{3} \mathrm{~J}_{\mathrm{C}-\mathrm{P}}=4.5 \mathrm{~Hz}, \mathrm{Ph}\right), 119.99,119.95(\mathrm{C}-5), 75.40,75.37$ $\left(\mathrm{OCH}_{2} \mathrm{C}\left(\mathrm{CH}_{3}\right)_{3}\right), 72.37\left(d,{ }^{3} \mathrm{C}-\mathrm{P}=11.9 \mathrm{~Hz}, \mathrm{OCH}_{2} \mathrm{CH}_{2} \mathrm{~N}\right), 72.26\left({ }^{3}{ }^{3} \mathrm{C}_{\mathrm{c}-\mathrm{P}}=12.9 \mathrm{~Hz}, \mathrm{OCH}_{2} \mathrm{CH}_{2} \mathrm{~N}\right)$, $67.51\left(d,{ }^{1} J_{C-P}=155.3 \mathrm{~Hz}, \mathrm{CH}_{2}-\mathrm{P}\right), 67.48\left(d,{ }^{1} \mathrm{~J}_{\mathrm{C}-\mathrm{P}}=155.3 \mathrm{~Hz}, \mathrm{CH}_{2}-\mathrm{P}\right)$, 51.02, $50.92(\mathrm{~N}-\mathrm{CH})$, 44.69, $44.65\left(\mathrm{~N}-\mathrm{CH}_{2}\right), 32.34\left(\mathrm{C}\left(\mathrm{CH}_{3}\right)_{3}\right), 26.77,26.74,\left(\mathrm{C}\left(\mathrm{CH}_{3}\right)_{3}\right), 21.26\left(d^{3}{ }^{3} \mathrm{C}_{\mathrm{c}-\mathrm{P}}=5.3 \mathrm{~Hz}, \mathrm{CH}_{3-}\right.$ aa), $20.74\left(d,{ }^{3} \mathrm{C}_{\mathrm{c}-\mathrm{P}}=5.3 \mathrm{~Hz}, \mathrm{CH}_{3}-a \mathrm{a}\right)$ ppm. ${ }^{31} \mathrm{P}$ NMR (202 MHz, MeOH-d$): \delta 23.71,22.68 \mathrm{ppm}$. MS (ES+) m/z: 513.49 [M+Na+]. Reverse-phase HPLC, eluting with $\mathrm{H}_{2} \mathrm{O} / \mathrm{MeOH}$ from 90/100 to 0/100 in $30 \mathrm{~min}$, Flow $=1 \mathrm{~mL} / \mathrm{min}, \lambda=263 \mathrm{~nm}, t_{R}=15.74 \mathrm{~min}$.

\section{COMMENTARY}

\section{Background Information}

Numerous studies have shown that aryloxy phosphoramidate nucleosides are able to enhance, in vitro and in vivo, the activity of parent nucleosides endowed with a variety of biological activities. As result of these studies several leading pharmaceutical companies have successfully taken advantage of this technology. Gilead, has just launched on the market its anti-HCV ProTide, Sofosbuvir (PSI-7977) and at the same time it has exploited this technology to create an advanced anti-HIV drug (GS 7340), which is now in Phase III clinical trial. Nucana Biomed has taken to trial a gemcitabine ProTide, (NUC-1031, Acelarin) for treating patients with advanced solid tumours. These prodrugs are usually prepared as 1:1 diastereomeric mixtures due to the formation of a new chiral center at the phosphorus atom. Most of these prodrugs that have entered into the clinic to date have been progressed as diastereoisomeric mixtures at the phosphate center. One exception is Sofosbuvir, which, due to a 18 -fold difference in activity between the two diastereoisomers, has been launched in the market as a single isomer resolved entity $(S p)$ at considerable difficulty and expense by Gilead. Up to now the phosphoramidate prodrugs could not be easily prepared in the form of single 
diastereoisomers because of lack of control of the stereochemistry at the phosphorus centre during the synthesis. For this reason more recently the notion of an achiral phosphate prodrug motif such as a symmetrical bis-amidate was re-explored.

Diamide prodrugs to mask a nucleoside monophosphate were indeed reported for the first time almost 20 years ago. Interestingly after the first appearence, no further reports ensued seeking to explore and optimize the utility of this class of nucleoside monophosphate prodrugs. Despite these disappointing earlier results and the slow evolution of this class, the result of these new investigations indicates the bis-amidate as a promising new phosphate prodrug motif for drug discovery.

In particular, researchers at Gilead Sciences were able to show the utility of diamide prodrugs applied to ANPs, a class of broad spectrum antiviral agents active against DNA viruses and retroviruses. A study seeking inhibitors of orthopoxvirus replication demonstrated that GS-8357, PMEA bis-amidate containing $L$-alanine n-butyl ester was as effective as the bis-POM prodrug in cellular antiviral assays, indicating effective cellular permeation and intracellular prodrug cleavage [Keith et al. 2003]. Later, they also reported the GS-9219, a PMEG (phospho-nomethoxyethylguanine) prodrug to selectively deliver the active agent to lymphoid cells [Reiser et al. 2008]. Similarly, several ANP phosphonodiamidates containing alkyl (L)-alanine were reported to exhibit potent antiviral activities, being GS-9191,bis(isobutyl- $(L)$ phenylalaninyl)phosphonodi-amidate-PME-N6 (cyclopropyl) DAP the most active of the series against Human papilloma Viruse (HPV) and currently in Phase I clinical trials as a topical prodrug for the treatment of HPV lesions.

\section{Critical Parameters and Troubleshooting}


The synthetic procedures described in this article, are intended for use only by persons with prior training in experimental organic chemistry and thus with knowledge of the common chemical laboratory techniques such as solvent evaporation, extraction, TLC, column chromatography and HPLC. Characterization of the products demands knowledge of monodimensional $\left({ }^{1} \mathrm{H},{ }^{13} \mathrm{C},{ }^{31} \mathrm{P}\right)$ and bidimensional (COSY, HSQC and HMBC) NMR experiments as well as of ESI mass spectroscopy.

General laboratory safety is also of primary concern when hazardous materials are involved. Strict adherence to the reported procedures is therefore highly recommended.

Anhydrous conditions are strictly required for both procedures reported. The solvents need to be dry and the nucleosides and the amino acids need to be dried under vacuum for $24 \mathrm{~h}$ prior their use. It is recommended to use $\mathrm{POCl}_{3}$ and $\mathrm{TMSBr}$ freshly distilled.

For basic protocol 1 the amino acid ester, if soluble, can be dissolved in dichloromethane and added via syringe to the reaction mixture. For diamidate prodrugs having a low $\log \mathrm{P}$ value, the aqueous work up must be avoided in order to minimize the lost of compound in the water phase.

In basic protocol 2 in step 12 depending on the compounds dichloromethane could be more efficient as extraction solvent. For basic protocol 2 all the extraction sequence are necessary and highly recommended in order to obtain pure product; they indeed help the purification process.

\section{Anticipated Results}

The protocols described here for exemplary bis-amidates prodrugs and three parent nucleosides can be applied to other nucleoside analogues and a wide range of amino acid esters. The yields of the desired products that can be expected vary from $12 \%$ to $46 \%$. 


\section{Time Considerations}

The synthesis of the phosphorodiamidate prodrugs can be accomplished in 2 days when following either basic protocol 1. Preparation of the phosphonodiamidate prodrugs according to basic protocol 2 requires 2 to 3 days. The amino acid ester can be prepared in 1 day.

\section{LITERATURE CITED}

Ariza, M. E. 2005. Current Prodrug Strategies for the Delivery of Nucleotides into Cells. Drug Design Reviews - Online 2: 273-387.

Derudas, M., Carta, D., Brancale, A., Vanpouille, C., Lisco, A., Margolis, L., Balzarini, J., McGuigan, C. 2009. The application of phosphoramidate protide technology to acyclovir confers anti-HIV inhibition. J. Med. Chem. 52: 5520-30.

He, G.-X., Krise, J. P., Oliyai, R. 2007. Prodrugs of Phosphonates, Phosphinates, and Phosphates. Springer 223-264: New York.

Hecker, S. J., Erion, M. D. 2008. Prodrugs of phosphates and phosphonates. J. Med. Chem. 51: 2328-45.

Jansa, P., Baszczyňski, O., Dračínský, M., Votruba, I., Zídek, Z., Bahador, G., Stepan, G., Cihlar, T., Mackman, R., Holý, A., Janeba, Z. 2011. A novel and efficient onepot synthesis of symmetrical diamide (bis-amidate) prodrugs of acyclic nucleoside phosphonates and evaluation of their biological activities. Eur. J. Med. Chem. 46: 3748-54

Keith, K. A., Hitchcock, M. J., Lee, W. A., Holy, A., Kern, E. R. . 2003. Evaluation of nucleoside phosphonates and their analogs and prodrugs for inhibition of orthopoxvirus replication. Antimicrob. Agents Chemother. 47: 2193-2198.

Krise, J. P., Stella, V. J. 1996. Prodrugs of phosphates, phosphonates, and phosphinates. Adv.Drug Deliver. Rev. 19: 287-310.

Li, F., Maag, H., Alfredson, T. 2007. Prodrugs of nucleoside analogues for improved oral absorption and tissue targeting. J. Pharm. Sci. 97: 1109-1134.

McGuigan, C., Bourdin, C., Derudas, M., Hamon, N., Hinsinger, K., Kandil, S., Madela, K., Meneghesso, S., Pertusati, F., Serpi, M., Slusarczyk, M., Chamberlain, S., Kolykhalov, A., Vernachio, J., Vanpouille, C., Introini, A., Margolis, L., Balzarini, J. 2013. Design, synthesis and biological evaluation of phosphorodiamidate prodrugs of antiviral and anticancer nucleosides. Eur. J. Med. Chem. 70: 326-340. 
McGuigan, C., Derudas, M., Gonczy, B., Hinsinger, K., Kandil, S., Pertusati, F., Serpi, M., Snoeck, R., Andrei, G., Balzarini, J., McHugh, T. D.; Maitra, A., Akorli, E., Evangelopoulos, D., Bhakta, S. 2014. ProTides of N-(3-(5-(2'-deoxyuridine))prop2-ynyl)octanamide as potential anti-tubercular and anti-viral agents. Bioorg. Med. Chem. 22: 2816-2824.

McGuigan, C., Gilles, A., Madela, K., Aljarah, M., Holl, S., Jones, S., Vernachio, J. H. J. Ames B., Bryant, K. D. 2010. Phosphoramidate ProTides of 2'-C-methylguanosine as highly potent inhibitors of Hepatitis C Virus. Study of their in vitro and in vivo properties. J. Med. Chem. 53: 4949-4957.

McGuigan, C., Madela, K., Aljarah, M., Bourdin, C., M., A., Barrett, E., Jones, S., Kolykhalov, A., Bleiman, K., Bryant, K. D., Ganguly, B., Gorovits, E., Henson, G., Hunley, D., Hutchins, J., Muhammad, J., Obikhod, A., Patti, J., Walters, C. R., Wang, J., Vernachio, J., Ramamurty, V. S. C., Battina, S. K.; S., C. 2011. Phosphorodiamidates as a Promising New Phosphate Prodrug Motif for Antiviral Drug Discovery: Application to Anti-HCV Agents. J. Med. Chem. 54: 8632-8645.

McGuigan, C., Murziani, P., Slusarczyk, M., Gonczy, B., Vande Voorde, J., Liekens, S., Balzarini, J. 2011. Phosphoramidate ProTides of the anticancer agent FUDR successfully deliver the preformed bioactive monophosphate in cells and confer advantage over the parent nucleoside. J. Med. Chem. 54: 7247-58.

McGuigan, C., Pathirana, R. N., Balzarini, J., De Clercq, E. 1993. Intracellular delivery of bioactive AZT nucleotides by aryl phosphate derivatives of AZT. J. Med. Chem. 36: 1048-1.

Mehellou, Y., Balzarini, J., McGuigan, C. 2009. Aryloxy Phosphoramidate triester: a technology for delivering monophosphorylated nucleosides and sugars into cells. ChemMedChem, 4: 1779-91.

Pertusati, F., Hinsinger, K., Flynn, Á. S., Powell, N., Tristram, A., Balzarini, J., McGuigan, C. 2014. PMPA and PMEA prodrugs for the treatment of HIV infections and human papillomavirus (HPV) associated neoplasia and cancer. Eur. J. Med. Chem. 78, 259-268.

Pertusati, F., Serpi, M., McGuigan, C. 2012. Medicinal chemistry of nucleoside phosphonate prodrugs for antiviral therapy. Antiviral Chem. Chemoth., 22: 181203.

Peterson, L. W., McKenna, C. E. 2009. Prodrug approaches to improving the oral absorption of antiviral nucleotide analogues. Exp. Opinion on Drug Deliv. 6: 405420.

Reiser, H., Wang, J., Chong, L., Watkins, W. J., Ray, A. S., Shibata, R., Birkus, G., Cihlar, T., Wu, S., Li, B., Liu, X., Henne, I. N., Wolfgang, G. H. I., Desai, M., Rhodes, G. R., Fridland, A., Lee, W. A., Plunkett, W., Vail, D.; Thamm, D. H., 
Jeraj, R.; Tumas, D. B. 2008. GS-9219-A Novel Acyclic Nucleotide Analogue with Potent Antineoplastic Activity in Dogs with Spontaneous Non-Hodgkin's Lymphoma. Clin. Cancer Res. 14: 2824-2832.

Schultz, C. 2003. Prodrugs of biologically active phosphate esters. Bioorg. Med. Chem., 11: 885-898.

Serpi, M., Bibbo, R., Rat, S., Roberts, H., Hughes, C., Caterson, B., Alcaraz, M. J., Gibert, A. T., Verson, C. R., McGuigan, C. 2012. Novel phosphoramidate prodrugs of $\mathrm{N}$-acetyl-(D)-glucosamine with antidegenerative activity on bovine and human cartilage explants. J. Med. Chem. 55: 4629-39.

Serpi, M., Madela, K., Pertusati, F., Slusarczyk, M. 2013. Synthesis of phosphoramidate prodrugs: ProTide approach. Curr. Protoc. Nucleic Acid Chem. 53: 15.5.1-15.5.15.

Slusarczyk, M., Lopez, M. H., Balzarini, J., Mason, M., Jiang, W. G., Blagden, S., Thompson, E.; Ghazaly, E., McGuigan, C. 2014. Application of ProTide Technology to Gemcitabine: A Successful Approach to Overcome the Key Cancer Resistance Mechanisms Leads to a New Agent (NUC-1031) in Clinical Development. J. Med. Chem. 57, 1531-1542.

Starrett, J. E. Jr., Tortolani, D. R., Russell, J., Hitchcock, M. J. M., Whiterock, V., Martin, J. C., Mansuri, M. M. 1994. Synthesis, Oral Bioavailability Determination, and in vitro Evaluation of Prodrugs of the Antiviral Agent 9-[2(Phosphonomethoxy)ethyl]adenine (PMEA). J. Med. Chem. 37: 1857-1864.

Toti, K. S., Derudas, M., Pertusati, F., Sinnaeve, D., Van den Broeck, F., Margamuljana, L., Martins, J. C., Herdewijn, P., Balzarini, J., McGuigan, C., Van Calenbergh, S. 2014. Synthesis of an Apionucleoside Family and Discovery of a Prodrug with Anti-HIV Activity. J. Org. Chem., 79: 5097-5112.

Wagner, C. R., Iyer, V. V., McIntee, E. J. 2000. Pronucleotides: Toward the in vivo delivery of antiviral and anticancer nucleotides. Med. Res. Rev. 20: 417-451.

Wolfgang, G. H. I., Shibata, R., Wang, J., Ray, A. S., Wu, S., Doerrfler, E., Reiser, H., Lee, W. A., Birkus, G., Christensen, N. D., Andrei, G., Snoeck, R. 2009. GS-9191, a Novel Topical Prodrug of the Nucleotide Analog PMEG (9-(2Phosphonylmethoxyethyl) guanine), with Anti-proliferative Activity and Possible Utility in the Treatment of HPV Lesions. Antimicrob. Agents Chemother. 53: 2777-2784. 